Pacific Journal of Mathematics

ABELIAN SUBGROUPS OF $p$-GROUPS 


\section{ABELIAN SUBGROUPS OF $p$-GROUPS}

\section{Charles HobBy}

Let $G$ be a finite $p$-group where $p$ is an odd prime. We say that $G$ has property $A_{n}$ if every abelian normal subgroup of $G$ can be generated by $n$ elements. Further, if $G_{n}$ denotes the $n$th element in the descending central series of $G$, we say that $G$ has property $A_{n}\left(G_{n}\right)$ if every abelian subgroup of $G_{n}$ which is normal in $G$ can be generated by $n$ elements. If $G$ has property $A_{1}$, then $G$ is cyclic. N. Blackburn [1] found all of the groups which have property $A_{2}$. It follows from the work of Blackburn that if $G$ has property $A_{2}$ then the derived group of $G$ is abelian and every subgroup of $G$ has property $A_{2}$. We shall show that if $G$ has property $A_{3}$ then every subgroup of $G$ has property $A_{3}$. There exist groups which have property $A_{3}$ in which the derived series is arbitrarily long [2] so no analogue of Blackburn's result on the derived group is possible. We next consider groups $G$ which have property $A_{n}\left(G_{n}\right)$ and show that $G_{n}$ can be generated by $n$ elements. This leads to the existence of a bound on the derived length of $G$ which depends only on $n$ and the exponent of $G_{n}$.

We shall use the following notation: $p$ is an odd prime; $G=G_{1} \supset G_{2} \supset \ldots$ is the descending central series of $G ; Z(G)=Z_{1}(G) \subset Z_{2}(G) \subset \cdots$ is the ascending central series of $G ; G^{(k)}$ is the $k$ th derived group of $G ;(H, K)$ is the subgroup of $G$ generated by all elements $(h, k)=h^{-1} k^{-1} h k$ for $h \in H, k \in K ; N \triangleleft G$ means $N$ is normal in $G ; N \subset G$ means $N$ is properly contained in $G ; C_{\theta}(N)$ is the centralizer of $N$ in $G ; H^{\theta}$ is the normal subgroup of $G$ generated by $H ; \sigma(G)$ is the subgroup generated by $p$ th powers of elements of $G . \quad \Omega(G)$ is the subgroup generated by all elements of order $p$ in $G ; \phi(G)$ is the Frattini subgroup of $G ;|G|$ is the order of $G$.

If $A \triangleleft G$ and $A \subset C_{G}(A)$, then there is a subgroup $B$ of $C_{\theta}(A)$ such that $B \triangleleft G$ and $[B: A]=p$. It follows that if a normal subgroup $A$ of $G$ is properly contained in an abelian subgroup $C$ of $G$, then $A$ is properly contained in some abelian normal subgroup $B$ of $G$.

Lemma 1. Suppose $A \triangleleft G$ and $A \subset C$ where $C$ is an elementary abelian subgroup of $G$. Then $G$ contains an elementary abelian normal subgroup $B$ such that $A$ is a subgroup of index $p$ in $B$.

Proof. Suppose $G$ is a group of minimal order for which the lemma is false. Then $C \subset G$, so there is a subgroup $M$ of index $p$ in $G$ which contains $C$. It follows that $M$ contains an elementary abelian normal subgroup $B_{1}$ such that $\left[B_{1}: A\right]=p$. Set $D=M \cap C_{G}(A)$. Then $B_{1} \triangleleft D \triangleleft G$.

Received May 29, 1962. 
Since $\left(D, B_{1}\right) \subseteq A$ and $(D, A)=1$, we have $B_{1} \subseteq Z_{2}(D) \triangleleft G$. Therefore $B_{1}^{G} \subseteq Z_{2}(D)$. But $Z_{2}(D)$ is a regular $p$-group for $p>2$, so $B_{1}^{G}$ has exponent p. Let $B$ be a subgroup of $B_{1}^{G}$ which is normal in $G$ and which contains $A$ as a subgroup of index $p$. Clearly $B$ is elementary abelian, so the lemma is true for $G$.

THEOREM 1. If $G$ has property $A_{3}$ then every subgroup of $G$ has property $A_{3}$.

Proof. Suppose $G$ is a group of minimal order for which the theorem is false. Then $G$ contains an elementary abelian normal subgroup $A$ of order $p^{3}$, and there is a subgroup $M$ of index $p$ in $G$ which does not have property $A_{3}$. It follows that $M$ contains an elementary abelian normal subgroup $D$ of order $p^{4}$. Let $N$ be a subgroup of order $p^{2}$ in $A$ which is contained in $M$ and which is normal in $G$. If we let $C=C_{\theta}(N)$, then $[G: C] \leqq p$, hence $[D: D \cap C] \leqq p$. Thus we may suppose that $N \subset D$, since otherwise we could choose a new subgroup $D_{1}$ in $(C \cap D) N$ such that $N \subset D_{1} \triangleleft M$ and $D_{1}$ is elementary abelian of order $p^{4}$.

Since $G$ has property $A_{3}$ it follows from Lemma 1 that $A$ contains the only elements of order $p$ in $C_{o}(A)$. Therefore $N=D \cap C_{o}(A)$. It is easy to see that $\left[C: C_{0}(A)\right] \leqq p^{2}$, thus $C=D C_{0}(A)$. Therefore, if $d \in D, g \in G$, then $g^{-1} d g=d_{1} c$ for some $d_{1} \in D, c \in C_{o}(A)$. We recall that $D$ is an abelian normal subgroup of $M$, and that $M \triangleleft G$. Thus $D$ and $g^{-1} D g$ generate a group of class at most two; hence for $p>2$ the group generated by $D$ and $g^{-1} D g$ has exponent $p$. Thus it follows from $g^{-1} d g=$ $d_{1} c$ that $c^{p}=1$, whence $c \in A$. Therefore $A D \triangleleft G$. But $A \cap D=N$, so $[A D: D]=p$. Since $D$ is not normal in $G$, we must have $A D=D\left(g^{-1} D g\right)$ for some element $g \in G$. Therefore $D \cap g^{-1} D g$ has order at least $p^{3}$ and is contained in $Z_{1}(A D)$ which is normal in $G$. Thus $A D$ must contain an element of order $p$ which centralizes $A$ and which does not belong to $A$. This is a contradiction.

THEOREM 2. If $G$ has property $A_{n}\left(G_{n}\right)$ then $G_{n}$ can be generated by $n$ elements.

Proof. Suppose $G$ is a group of minimal order for which the theorem is false. Then $G_{n}$ is not abelian, so $\phi\left(G_{n}\right) \neq 1$. Let $Z$ be a group of order $p$ in $Z_{1}(G) \cap \phi\left(G_{n}\right)$. Then $G_{n}$ and $(G / Z)_{n}$ have the same number of generators, so $(G / Z)_{n}$ must contain an elementary abelian subgroup $B \mid Z$ of order $p^{n+1}$ which is normal in $G / Z$. Let $B$ be the preimage of $B / Z$ in $G$. Then $B \triangleleft G, B$ has order $p^{n+2}$, and $B^{(1)} \leqq Z$. Thus $B$ has class at most two, hence is regular for $p>2$. But $\sigma(B) \subseteq Z$, so $\Omega(B)$ is a group of order at least $p^{n+1}$ which is normal in $G$. Thus there is 
a subgroup $A$ of $\Omega(B)$ such that $A \triangleleft G, \sigma(A)=1$, and $A$ has order $p^{n+1}$. Let $N$ be a subgroup of index $p$ in $A$ which is normal in $G$. Then $|N|=$ $p^{n}$ and $N \triangleleft G$ imply $N \subseteq Z_{n}(G)$, whence $N \subseteq Z_{1}\left(G_{n}\right)$. Therefore $A$ is abelian, a contradiction.

CoRollary. Suppose $G$ has property $A_{n}\left(G_{n}\right)$, where $G_{n}$ has exponent $p^{m}$. Let $k$ be an integer such that $2^{k} \geqq n$. Then $G^{(k+m)}=1$.

Proof. By Theorem $2, G_{n}$ can be generated by $n$ elements. Therefore [3, Theorem 2] $\phi\left(G_{n}\right)=\Omega\left(G_{n}\right)$. It follows that $G_{n}^{(m)}=\langle 1\rangle$ [4, Theorem 2]. In any $p$-group, $G^{(t)} \leqq G_{2}$. Therefore $G^{(k)} \leqq G_{n}$, whence $G^{(k+m)}=\langle 1\rangle$.

\section{REFERENCES}

1. N. Blackburn, Generalizations of certain elementary theorems on p-groups, Proc. London Math. Soc., (3) 11 (1961), 1-22.

2. C. Hobby, The derived series of a finite p-group, Illinois J. Math., 5 (1961), 228-233.

3. - Generalizations of a theorem of N. Blackburn on p-groups, Illinois J. Math., 5 (1961), 225-227.

4. — A characteristic subgroup of a p-group, Pacific J. Math., 10 (1960), 853-858.

UNIVERSITY OF WASHINGTON 



\section{PACIFIC JOURNAL OF MATHEMATICS}

\section{EDITORS}

\author{
Ralph S. Phillips \\ Stanford University \\ Stanford, California \\ M. G. Arsove \\ University of Washington \\ Seattle 5 , Washington
}

\author{
A. L. Whiteman \\ University of Southern California \\ Los Angeles 7, California \\ Lowell J. Paige \\ University of California \\ Los Angeles 24, California
}
E. F. BECKENBACH
D. DERRY
ASSOCIATE EDITORS
T. M. CHERRY
M. OHTSUKA
H. L. ROYDEN
E. G. STRAUS
E. SPANIER
F. WOLF

\section{SUPPORTING INSTITUTIONS}

\author{
UNIVERSITY OF BRITISH COLUMBIA \\ CALIFORNIA INSTITUTE OF TECHNOLOGY \\ UNIVERSITY OF CALIFORNIA \\ MONTANA STATE UNIVERSITY \\ UNIVERSITY OF NEVADA \\ NEW MEXICO STATE UNIVERSITY \\ OREGON STATE UNIVERSITY \\ UNIVERSITY OF OREGON \\ OSAKA UNIVERSITY \\ UNIVERSITY OF SOUTHERN CALIFORNIA
}

\author{
STANFORD UNIVERSITY \\ UNIVERSITY OF TOKYO \\ UNIVERSITY OF UTAH \\ WASHINGTON STATE UNIVERSITY \\ UNIVERSITY OF WASHINGTON \\ AMERICAN MATHEMATICAL SOCIETY \\ CALIFORNIA RESEARCH CORPORATION \\ SPACE TECHNOLOGY LABORATORIES \\ NAVAL ORDNANCE TEST STATION
}

Mathematical papers intended for publication in the Pacific Journal of Mathematıcs should be typewritten (double spaced), and the author should keep a complete copy. Manuscripts may be sent to any one of the four editors. All other communications to the editors should be addressed to the managing editor, L. J. Paige at the University of California, Los Angeles 24, California.

50 reprints per author of each article are furnished free of charge; additional copies may be obtained at cost in multiples of 50 .

The Pacific Journal of Mathematics is published quarterly, in March, June, September, and December. Effective with Volume 13 the price per volume (4 numbers) is $\$ 18.00$; single issues, $\$ 5.00$. Special price for current issues to individual faculty members of supporting institutions and to individual members of the American Mathematical Society: $\$ 8.00$ per volume; single issues $\$ 2.50$. Back numbers are available.

Subscriptions, orders for back numbers, and changes of address should be sent to Pacific Journal of Mathematics, 103 Highland Boulevard, Berkeley 8, California.

Printed at Kokusai Bunken Insatsusha (International Academic Printing Co., Ltd.), No. 6, 2-chome, Fujimi-cho, Chiyoda-ku, Tokyo, Japan.

PUBLISHED BY PACIFIC JOURNAL OF MATHEMATICS, A NON-PROFIT CORPORATION

The Supporting Institutions listed above contribute to the cost of publication of this Journal, but they are not owners or publishers and have no responsibility for its content or policies. 


\section{Pacific Journal of Mathematics}

\section{Vol. 12 , No. 4 \\ April, 1962}

Tsuyoshi Andô, On fundamental properties of a Banach space with a cone ..... . 1163

Sterling K. Berberian, A note on hyponormal operators ................ 1171

Errett Albert Bishop, Analytic functions with values in a Frechet space . . . . . . . 1177

(Sherman) Elwood Bohn, Equicontinuity of solutions of a quasi-linear equation ............................................ 1193

Andrew Michael Bruckner and E. Ostrow, Some function classes related to the class of convex functions . . . . . . . . . . . . . . . . . . . . . . . . 1203

J. H. Curtiss, Limits and bounds for divided differences on a Jordan curve in the complex domain . . ................................. 1217

P. H. Doyle, III and John Gilbert Hocking, Dimensional invertibility . . . . . . . . 1235

David G. Feingold and Richard Steven Varga, Block diagonally dominant matrices and generalizations of the Gerschgorin circle theorem ................. 1241

Leonard Dubois Fountain and Lloyd Kenneth Jackson, A generalized solution of the boundary value problem for $y^{\prime \prime}=f\left(x, y, y^{\prime}\right) \ldots \ldots \ldots \ldots \ldots \ldots \ldots \ldots \ldots$

Robert William Gilmer, Jr., Rings in which semi-primary ideals are primary. . . . . 1273

Ruth Goodman, K-polar polynomials .......................... 1277

Israel Halperin and Maria Wonenburger, On the additivity of lattice completeness ........................................... 1289

Robert Winship Heath, Arc-wise connectedness in semi-metric spaces . . . . . . . . 1301

Isidore Heller and Alan Jerome Hoffman, On unimodular matrices . . . . . . . . . . . 1321

Robert G. Heyneman, Duality in general ergodic theory . . . . . . . . . . . . . . . 1329

Charles Ray Hobby, Abelian subgroups of p-groups . . . . . . . . . . . . . . . 1343

Kenneth Myron Hoffman and Hugo Rossi, The minimum boundary for an analytic

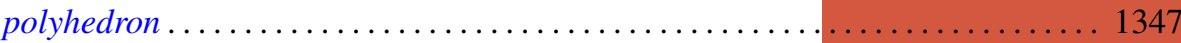

Adam Koranyi, The Bergman kernel function for tubes over convex cones ........ 1355

Pesi Rustom Masani and Jack Max Robertson, The time-domain analysis of a continuous parameter weakly stationary stochastic proces.

William Schumacher Massey, Non-existence of almost-complex structures on

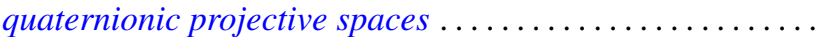

Deane Montgomery and Chung-Tao Yang, A theorem on the action of $\mathrm{SO}(3) \ldots . .1385$

Ronald John Nunke, A note on Abelian group extensions . . . . . . . . . . . . . 1401

Carl Mark Pearcy, A complete set of unitary invariants for operators generating finite $W^{*}$-algebras of type $I$

Edward C. Posner, Integral closure of rings of solutions of linear differential equations.

Duane Sather, Asymptotics. III. Stationary phase for two parameters with an application to Bessel functions.

J. Śladkowska, Bounds of analytic functions of two complex variables in domains

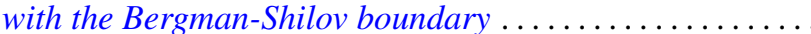

Joseph Gail Stampfli, Hyponormal operators .

George Gustave Weill, Some extremal properties of linear combinations of kernels

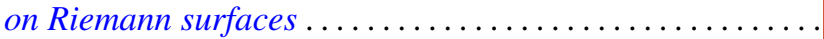

